\title{
EFEITOS DE HERBICIDAS E POPULAÇŌES DE PLANTAS NA NODULAÇĀO E PRODUÇÃO DA SOJA (Glycine max (L.) Merril 'Santa Rosa')
}

\section{RESUMO}

Três experimentos de campo e um em vasos foram conduzidos com a cultura da soja 'Santa Rosa', para estudar os efeitos da aplicacão de diferentes herbicidas, combinados com diferentes populações de plantas, sobre a nodulação, produção de grãos e teor de $\mathrm{N}$ em grãos. Utilizaram-se solos argiloso e muito argiloso no campo e argiloso e barrento em vasos.

Os herbicidas aplicados foram o trifluralin a $0,96 \mathrm{~kg} / \mathrm{ha}$ e o vernolate a $3,60 \mathrm{~kg} / \mathrm{ha}$, incorporados ao solo; alachlor a $2,40 \mathrm{~kg}$; pendimethalin a 1,50 $\mathrm{kg}$ em dois experimentos e a $1,25 \mathrm{~kg}$ em um e o metribuzin a $0,63 \mathrm{~kg}$ em dois e a $0,53 \mathrm{~kg}$ em um em pré-emergência no campo. Em vasos, as doses foram as mesmas, exceto do trifluralin, que foi de $0,86 \mathrm{~kg}$. Havia um tratamento sem herbicida em cada experimento.

As densidades de semeadura corresponde ram, no Experimento I, a 200 e 300 mil plantas/ha, no Experimento II a 200, 300 e 400 mil plantas/ha e, no III, a 150 e 250 mil plantas/ha. Em cada vaso, foram semeadas três plantas e nestes, fez-se o estudo do crescimento até 30 dias, quando se coletaram os nódulos.

No campo, em pleno florescimento, foram amostrados os nódulos de cinco plantas por parcela, que foram contados e pesados após secagem. Na colheita, foram obtidos a produção de grãos e o seu teor de $\mathrm{N}$.

As diferentes densidades não causaram alte ração no número e no peso de nódulos. Em vasos a modulação foi afetada, na fase inicial, por trifluralin, pendimethalin e vernolate, que reduziram o número e o peso de nódulos. O trifluralin reduziu es ses valores no campo, na fase de máxima nodulação, em um experimento.

O aumento da população causou elevação do teor de $\mathrm{N}$, e de grãos na colheita, em dois experi-

\section{R. DEUBER*, P.N. CAMARGO** \& L.H. SIGNORI ${ }^{* * *}$}

* Pesquisador Científico, Seção de Fisiologia, Instituto Agronômico. Caixa Postal 28, 13.100, Campinas, SP.

** Professor assistente Doutor, Depart. Química, ESALQ, Piracicaba.

*** Biologista, Centro Experimental de Campi nas, Instituto Agronômico.

Parte da Tese de Doutorado do primeiro autor.

mentos. Nenhum herbicida afetou o teor desse nutriente nas folhas ou nos grãos.

A produção de grãos por área foi elevada com o aumento da população de plantas. O metribuzin causou redução da produção em um experimento. PALAVRAS-CHAVE:

Glycine $\max ($ L.) Merril, herbicidas, nodulação, população de plantas, produção.

\section{SUMMARY}

EFFECTS OF HERBICIDES AND PLANT POPULATIONS ON NODULATION AND YIELD IN SOYBEANS Glycine $\max (L$. MERRIL 'SANTA ROSA'

The effects of herbicides and plant popula tions on nodulation and yield in soybean Santa Rosa' were studied in three Experiments in field conditions and one in greenhouse. Clay and very clay soils were used in the field and very clay and loamy soils in pots.

Trifluralin at $0,96 \mathrm{~kg} / \mathrm{ha}$ and vernolate at 3,60 $\mathrm{kg} / \mathrm{ha}$, preplant incorporated; pendimethalin at $1,50 \mathrm{~kg} / \mathrm{ha}$, in two experiments, and at 1,25 in a third; alachlor at $2,40 \mathrm{~kg}$; and metribuzin at 0,63 $\mathrm{kg}$ in two experiments and at $0,53 \mathrm{~kg}$ in a third, preemergence were applied in field conditions. In pots, the same rates were used, except for triflu ralin which was applied at $0,86 \mathrm{~kg} / \mathrm{ha}$. A check was included in all experiments.

All treatments in the field were combined with different plant densities: 200 and 300 thou sand in Experiment I, 200, 300 and 400 thousand in Experiment II and 150 and 250 thousand in Experiment III. Three plants per pot were studied in the greenhouse experiment during the first 30 days.

No interaction between herbicides and plant 
populations was observed for any of the studied parameters.

The plant density increase caused increase of yield and in the $\mathrm{N}$ concentration in grains in two experiments.

The different densities caused no change on the number or weight of nodules. Nodulation was affected, in pots, at its beginning, by trifluralin, pendimethalin and vernolate, with reduction of number and weight of nodules. Trifluralin depres sed these values also in the field, in one experiment, at flower stage set.

Grain yield was enhanced with population increase. Metribuzin reduced yield in one experiment.

\section{KEYWORDS:}

Glycine $\max (L$.$) Merril, herbicides, nodula-$

tion, plant population, grain yield.

\section{INTRODUÇÃO}

A cultura da soja no Brasil vem apresentando um crescimento contínuo e extraordinário, nos últimos dez anos, tornando-se, este país, o segundo maior produtor dessa leguminosa.

O estímulo de precos que a soja tem recebido no mercado internacional levou os agricultores a investir cada vez mais na tecnificação dessa cultura. O uso de herbicidas tem, assim, acompanhado o crescimento da soja, sendo esta cultura a que apresenta o maior indice e o maiór consumo desses defensivos no Brasil atualmente.

$O$ uso dos herbicidas tem crescido mais rapidamente do que as pesquisas básicas de seu comportamento no ambiente e sobre seus possiveis efeitos sobre as plantas e a microflora do solo.

Foram realizados alguns trabalhos sobre o efeito de herbicidas sobre bactérias Rhizobium sp verificando-se, às vezes, algum efeito inibitório sobre a nodulação $(16,22,29)$. Trabalho realizado por Giardini et al. (13) mostrou que em dois anos consecutivos, os herbicidas trifluralin, vernolate ou alachlor, aplicados no mesmo local, não causaram qualquer efeito inibitório sobre a nodulação de soja.

Para verificar os possiveis efeitos dos principais herbicidas utilizados no Brasil, em soja, sobre a nodulação no início do ciclo ou na fase de pleno florescimento, foram instalados três experimentos de campo e um em casa-de-vegetação, com diferentes tipos de solos.

\section{MATERIAIS E MÉTODOS}

Três experimentos de campo foram instalados em áreas do Centro Experimental de Campinas, do Instituto Agronômico, e um em casa de vegetacão, em diferentes solos, com a cultura da soja (Glycine $\max$ L. Merril). Utilizou-se o cultivar Santa Rosa que ê tardio, com ciclo vegetativo ao redor de 135 dias e crescimento determinado.

Os herbicidas utilizados nos experimentos foram:

alachlor: 2 -cloro-2',6'-dietil - metoximetilacetanilida, formulado como concentrado emulsionável, contendo $480 \mathrm{~g}$ de i.a. por litro( $\left.{ }^{1}\right)$

metribuzin: 4-amino-6-t-butil - 3 - metiltio - 1, 2,4,triazina-5- $(4 \mathrm{H})$-ona, formulado como pó molhável, contendo $70 \%$ de i.a. $\mathrm{p} / \mathrm{p}(2)$;

pendimethalin: N-(1-etilpropil)-3,4-dimetil - 2,6 - dinitrobenzenamina, formulado como concentrado emulsionável contendo 500 g de i.a. por litro( $\left.{ }^{3}\right)$

trifluralin: ", " "-trifluoro-2,6-dinitro - N,N-dipro pil-ptoluidina, formulado co mo concentrado emulsionável contendo 480 g de i.a. por litro $\left({ }^{4}\right)$;

vernolate: S-propil-dipropil - tiolcarbamato, formulado como concentrado emulsionável contendo $720 \mathrm{~g}$ de i. a. por litro $(5)$

Nos três experimentos de campo, utilizou-se o delineamento de blocos ao acaso, com quatro repetições e, parcelas medindo 7,0 metros de comprimento por 2,4 metros de largura em espaçamento de 0,6 metros entre linhas, obtendo-se três linhas úteis e duas de bordadura.

As aplicações dos herbicidas no campo foram sempre realizadas com um pulverizador costal de pressão constante de $2,81 \mathrm{~kg} / \mathrm{cm}^{2}$ impulsionado a gás carbônico, com gasto de água equivalente a 400 litros por hectare.

As sementes de soja, utilizadas em todos os experimentos, foram sempre tratadas com fungicida thiabendazole em pó e inoculadas com Rhizobium japonicum mantidas em meio turfoso.

Nos primeiros experimentos de campo, foi feita adubação a lanço, em área total, com $80 \mathrm{~kg} /$ /ha de $\mathrm{P}_{2} \mathrm{O}_{3}$, e incorporação com grade, 20 dias antes da semeadura. No terceiro experimento, a adubação foi nos sulcos, colocando-se, 3,5 g de $\mathrm{P}_{2} \mathrm{O}_{3}$, por metro linear. No experimento em vasos não se fez adubação.

Experimento I - 1977/78

Foi instalado em um Latossolo Vermelho Escuro orto, série Barão (25) apresentando as caracte rísticas físicas e químicas constantes no Quadro 1. Os tratamentos aplicados foram: trifluralin a $0,96 \mathrm{~kg} / \mathrm{ha}$ e vernolate a $3,60 \mathrm{~kg} / \mathrm{ha}$, aplicados prê- semeadura com incorporação; alachlor a 2,40 $\mathrm{kg} / \mathrm{ha}$; pendimethalin a $1,50 \mathrm{~kg} / \mathrm{ha}$, metribuzin a $0,63 \mathrm{~kg} / \mathrm{ha}$, aplicados após semeadura em pré-emergência; e, uma testemunha capinada. Cada tratamento foi combinado com densidade de semeadura de 200.000 e 300.000 plantas por hectare.

(1) Laç 4E; (') Sencor; (') Herbadox 500E; (1) Trenan; (1) Vernan 6E 
A aplicação dos herbicidas trifluralin e vernolate foi realizada no dia 17 de novembro de 1977 , entre 14:30 e 15:30 horas, com incorporacão imediata ao solo à uma profundidade de $0,08 \mathrm{~m}$ com grade dupla de discos. O solo apresentava-se úmido a $0,02 \mathrm{~m}$ da,superficie, o cêu claro e havia vento fraco.

No dia 20, fez-se a sulcação das parcelas com sulcador a tração animal e no dia 21 , a semeadura, manualmente, com 20 sementes por metro linear para a densidade 1 e 25 sementes para a densidade 2

Os herbicidas alachlor, pendimethalin e metribuzin foram aplicados no dia 24, entre 14:00 e 15:30 horas, estando o céu nublado, o solo seco na superficie, sem vento.

A emergência da cultura ocorreu no dia 28 do mesmo mês e o experimento todo foi capinado 43 dias após.

Aos 98 dias após a emergência, foram arrancadas, cuidadosamente, cinco plantas por parcela para separação dos nódulos das raízes que foram contados e, após secagem a $65^{\circ} \mathrm{C}$, pesados.

A colheita foi realizada com ciclo de 148 dias, obtendo-se a produção e o teor de $\mathrm{N}$ nos grãos. Os dados foram submetidos à análise estatística, sendo os valores de número e peso de nódulos transformados para $\mathbf{V} \mathbf{x}$.

\section{Experimento II - 1977/78}

Foi instalado em um Latossolo Roxo, série Chapadão (25), apresentando as características fisicas e químicas constantes no Quadro 1, para os primeiros $0,20 \mathrm{~m}$ de profundidade.

Os tratamentos foram os mesmos do experimento anterior, sendo cada um combinado com densidades de semeadura de 200.000, 300.000 e 400.000 plantas por hectare.

A aplicação dos herbicidas trifluralin e vernolate foi realizada no dia 18 de novembro de 1977, das 9:00 às 9:30 horas, com céu aberto, vento sul fraco, solo seco na superficie, incorporando imediatamente após, com grade dupla de discos

A semeadura foi realizada, manualmente, no dia 22 , colocando-se 20,25 e 35 sementes por metro linear, para as densidades 1,2 e 3 , respectivamente.

Os tratamentos pendimethalin, alachlor e metribuzin foram aplicados no dia 25 das 8:00 às 9:00 horas, com céu totalmente nublado, solo bem úmido e sem vento. A emergência da cultura ocorreu no dia 28. Aos 31 dias após fez-se aplicação de inseticida fosforado e aos 43 dias, capina geral do experimento.

Aos 94 dias, foram arrancadas, cuidadosa mente, cinco plantas par parcela para obtenção do número e peso de nódulos secos.

A colheita foi feita com ciclo de 148 dias, obtendo-se a produção de grãos e o teor de $\mathrm{N}$ nos mesmos.

\section{Experimento III $-1978 / 79$}

Foi instalado no mesmo solo do Experimento I. As características constam no Quadro 1.

Os tratamentos aplicados foram os mesmos sendo a dose de metribuzin reduzida para $0,53 \mathrm{~kg} /$ / ha e a do pendimethalin reduzida para $1,25 \mathrm{~kg} /$ /ha. Cada tratamento foi combinado com densidades de semeadura de 150.000 e 250.000 plantas por hectare.

O trifluralin e o vernolate foram aplicados dia
8 de novembro de 1978 , das 15:30 às 16:00 horas, estando o solo seco na superfície, o céu claro e sem vento, com incorporação imediata.

A semeadura foi feita no dia seguinte, com semeadeira Planet Junior. Os herbicidas de pré-emergência foram aplicados dia 10, das 14:00 às 15:00 horas, com céu encoberto e tempo chuvoso. A emergência ocorreu dia 15. 0 tratamento testemunha foi capinado 27 dias após.

A amostragem para coleta de nódulos foi feita aos 71 dias da mesma maneira e a colheita com um ciclo de 167 dias, obtendo-se os mesmos parâmetros.

\section{Experimento em casa-de-vegetação}

Foi instalado em 23 de novembro de 1978, utilizando-se o horizonte A. de dois latossolos, barrento e argiloso, cujas características estão no Quadro 1

O experimento foi conduzido em vasos, sendo uma parte constituída de vasos de aluminio, medindo $13 \mathrm{~cm}$ de diâmetro da boca e $16,5 \mathrm{~cm}$ de altura, com capacidade de dois litros e, outra parte de sacos plásticos medindo $13 \mathrm{~cm}$ de diâmetro da boca e $27 \mathrm{~cm}$ de altura com capacidade de 3,5 litros.

Os tratamentos aplicados foram os mesmos do Experimento I, sendo a dose de trifluralin reduzida para $0,86 \mathrm{~kg} / \mathrm{ha}$

Os herbicidas foram aplicados com pulveriza dor manual de pressão variável, de dois litros, gastando-se $125 \mathrm{ml}$ de água por metro quadrado. Os vasos de cada tratamento foram distribuídos ao acaso, sobre uma área de dois metros quadrados, fazendo-se a aplicação dos herbicidas sobre a mesma. O trifluralin e o vernolate foram aplicados antes de se fazer a semeadura. A seguir, retrouse a terra até a profundidade de dez centímetros, a partir da boca, incorporando-se uniformemente os herbicidas em um lençol plástico. Recolocou-se, então, terra até cinco centímetros e colocaram-se cinco sementes, completando com terra até a boca. Os demais herbicidas foram aplicados na superficie dos vasos com as sementes já colocadas a cinco centímetros.

O delineamento foi o totalmente casualizado, com três repetições para cada tratamento e cada época de amostragem, que foram realizadas aos 9,19 e 30 dias após a emergência. As plantas foram raleadas para três após a emergência. Para a amostragem aos 9 dias, foram utilizados os vasos de alumínio e, para as outras duas, os sacos plásticos.

Em cada amostragem, foram separados os caules, folhas e as raizes das três plantas e, após secagem a $65^{\circ} \mathrm{C}$, obtidos os pesos de matéria seca de cada parte.

$\mathrm{Na}$ terceira amostragem, foram separados, também, os nódulos das raízes, contados e, após secagem a $65^{\circ} \mathrm{C}$, pesados

Todos os dados obtidos foram analisados, procurando verificar a existência de interação solo $\mathrm{x}$ herbicidas. Os valores de número e peso de nódulos foram transformados rara $\quad \mathbb{X}$.

\section{RESULTADOS E DISCUSSÃO}

Nodulação

Os resultados de nodulação dos três 
Quadro 1. Características fisicas e quimicas dos solos em que se instalaram os experimentos de herbicidas em soja no campo e em casa-de-vegetaçāo no Centro Experimental de Campinas.

\begin{tabular}{|c|c|c|c|c|c|}
\hline \multirow[b]{2}{*}{ CARACTERISTICAS } & \multirow[b]{2}{*}{$\begin{array}{l}\text { EXPERIMENTO I } \\
1977-78\end{array}$} & \multirow{2}{*}{$\begin{array}{c}\text { CAMPO } \\
\text { EXPERIMENTO II } \\
1977-78\end{array}$} & \multirow[b]{2}{*}{$\begin{array}{c}\text { EXPERIMENTO III } \\
1978-79\end{array}$} & \multicolumn{2}{|c|}{ CASA-DE-VEGETAÇÃ̄O } \\
\hline & & & & $\begin{array}{r}\text { SOLO "A" } \\
197\end{array}$ & SOLO "B" \\
\hline Teor de argila $(\%)$ & 40 & 66 & 40 & 67 & 27 \\
\hline Teor de limo (\%) & 0 & 6 & 1 & 5 & 0 \\
\hline Teor de areia fina $(\%)$ & 23 & 9 & 17 & 12 & 30 \\
\hline Teor de areia grossa $(\%)$ & 37 & 19 & 42 & 16 & 43 \\
\hline $\mathrm{pH}$ & 5,8 & 4,8 & 6,6 & 5,7 & 5,4 \\
\hline Teor de matéria orgânica $(\%)$ & 1,7 & 3,9 & 3,1 & 2,7 & 3,4 \\
\hline Teor de $\mathrm{Ca}^{++}$(e. mg/100 ml TFSA) & 1,3 & 1,7 & 2,3 & 1,8 & 2,1 \\
\hline Teor de $\mathrm{Mg}^{++}$(e. $\mathrm{mg} / 100 \mathrm{ml}$ TFSA) & 0,6 & 0,4 & 1,1 & 0,5 & 0,5 \\
\hline Teor de $\mathrm{K}(\mu \mathrm{g} / \mathrm{ml}$ de TFSA) & 34 & 41 & 53 & 40 & 63 \\
\hline Teor de $\mathrm{P}(\mu \mathrm{g} / \mathrm{ml}$ de TFSA) & 6 & 7 & 2 & 2 & $100^{+}$ \\
\hline Classe textural & argiloso & muito argiloso & argiloso & muito argiloso & barrento \\
\hline
\end{tabular}


experimentos de campo estão nos Quadros 2,3 e 4 . As amostragens foram realizadas em épocas de pleno florescimento, quando se considera que a nodulação esteja no seu climax. Os dados de nodulação inicial, em vasos, constam no Quadro 5.

Os únicos efeitos de herbicidas verificados no cam po foram para peso unitário no Experimento II e, para número e peso total de matéria seca de nódulos, no Experimento III. Naquele, o vernolate apresentou os menores pes os unitários, diferindo do tratamento com pendimethalin e da testemunha, com os valores mais elevados.

No Experimento III ocorreu interação entre população e herbicidas. Com trifluralin, verificou-se o menor número e o peso mais baixo de nódulos, nas duas populações, mas somente houve diferenças significativas para a população mais baixa de plantas. Quanto ao número de nódulos, o trifluralin só não diferiu do tratamento com pendimetha lin e, para o peso de matéria seca, diferiu de todos os demais.

Quanto à população de plantas, só ocorreu diferença significativa para o peso de matéria seca de nódulos no primeiro experimento, com valores menores por planta com a população menor. Em nenhum caso, as populações afetaram o número ou $\mathrm{o}$ peso unitário. Isso mostra que dentro dos limites de população estudados, não houve influência considerável sobre o desenvolvi mento das bactérias.

Nos vasos já se verificava a ocorrência de nódulos pequenos em algumas plantas, em todos os tratamentos e, aos 19 dias, já havia muitas plantas com nódulos.

Para o número de nódulos, não foi encon trada inter ação solos $\mathrm{x}$ herbicidas, ocorrendo, entretanto, diferenças entre solos e entre herbicidas, a nivel de $1 \%$. Os tratamentos com trifluralin, vernolate e pendimethalin apresentaram os números mais baixos de nódu-

Quadro 2. Resultados de nodulação, teor de N e produção no Experimento I, de 1977 /78, de herbicidas e populações de plantas em soja 'Santa Rosa', em solo argiloso. Médias de quatro repetições.

\begin{tabular}{|c|c|c|c|c|c|c|c|}
\hline \multirow[b]{2}{*}{ TRATAMENTO } & \multirow[b]{2}{*}{ L.a./ha } & \multicolumn{3}{|c|}{ NóduLos (1) } & \multicolumn{2}{|c|}{$N^{(2)}$} & \multirow{3}{*}{$\begin{array}{c}\text { PRODUÇĀO } \\
\text { DE GRĀOS } \\
\mathrm{kg} / \mathrm{ha} \\
\end{array}$} \\
\hline & & NÛ́MERO & PESO MS & UNIT ÁRIO & FOLHAS & GRÃOS & \\
\hline & kg & & $\mathrm{g}$ & mg & $\%$ & $\%$ & \\
\hline \multicolumn{8}{|l|}{$P_{1}$} \\
\hline 1 - Vernolate & 3,60 & 1023 & 1,784 & 1,74 & 3,76 & 7,86 & 1.083 \\
\hline 2 - Trifluralin & 0,96 & 913 & 1,869 & 2,04 & 3,65 & 8,01 & 1.212 \\
\hline 3 - Pendimethalin & 1,50 & 691 & 1,344 & 1,94 & 3,82 & 7,96 & 1.170 \\
\hline 4 - Alachlor & 2,40 & 698 & 1,500 & 2,15 & 4,04 & 8,14 & 1.062 \\
\hline 5 - Metribuzin & 0,63 & 790 & 1,889 & 2,39 & 3,92 & 7,94 & 1.066 \\
\hline 6 - Sem herbicida & -- & 887 & 1,393 & 1,57 & 4,21 & 7,98 & 1.267 \\
\hline \multicolumn{8}{|l|}{$\mathbf{P}_{2}$} \\
\hline 7 - Vernolate & 3,60 & 718 & 1,279 & 1,78 & 3,92 & 8,09 & 1.132 \\
\hline 8 - Trifluralin & 0,96 & 758 & 1,428 & 1,88 & 4,14 & 8,23 & 1.104 \\
\hline 9 - Pendimethalin & 1,50 & 605 & 0,981 & 1,62 & 3,69 & 8,34 & 1.167 \\
\hline 10 - Alachlor & 2,40 & 606 & 1,266 & 2,09 & 4,11 & 8,05 & 1.269 \\
\hline 11 - Metribuzin & 0,63 & 584 & 1,042 & 1,78 & 3,97 & 8,33 & 1.092 \\
\hline 12 - Sem herbicida & -- & 852 & 1,764 & 2,07 & 3,89 & 8,30 & 1.043 \\
\hline F (herbicidas) & & $1,17 \mathrm{n.s}$ & 0,96 n.s. & 1,73 n.s. & 2,26 n.s. & 0,49 n.5. & 0,69 n.s. \\
\hline F (populaçōes) & & $4,04 \mathrm{n} . \mathrm{s}$ & $5,91 * *$ & $0,87 \mathrm{n} . \mathrm{s}$. & 0,63 n.s. & $10,03^{* *}$ & 0,09 n.s. \\
\hline C.V. & & $17,3 \%$ & $16.7 \%$ & $18,9 \%$ & $5,9 \%$ & $3,36 \%$ & $11,0 \%$ \\
\hline
\end{tabular}

(1) = amostragem de nodulação realizada aos 98 dias. Valores relativos a dez plantas.

(2) = amostragem de folhas realizadas aos 84 dias e de gräos, na colheita

Ms = matéria seca

n.s. = não significativo; ${ }^{* *}$ significativo ao nível de $1 \% ; P_{1}=200.000$ plantas $/$ ha e $P_{2}=300.000$ plantas $/$ ha 
Quadro 3. Resultados de nodulaçáo, teor de N e produção de gráos, no Experimento II, de 1977/78, de herbicidas e população de plantas em soja 'Santa Rosa', em solo muito argiloso. Médias de quatro repetiçōes.

\begin{tabular}{|c|c|c|c|c|c|c|c|}
\hline \multirow{2}{*}{ TRATAMENTO } & \multirow{2}{*}{$\begin{array}{l}\text { is./ha } \\
\mathrm{kg} \\
\end{array}$} & \multirow{2}{*}{ NÚMERO } & \multirow{2}{*}{$\begin{array}{c}\text { NODULOS } \\
\text { PESO MS } \\
\text { g }\end{array}$} & \multirow{2}{*}{$\begin{array}{c}\text { UNITẢRIO } \\
\text { mg } \\
\end{array}$} & \multicolumn{2}{|c|}{ TEOR DE N ${ }^{(2)}$} & \multirow{2}{*}{$\begin{array}{c}\text { PRODUÇĀO DE } \\
\text { GRÃOS } \\
\mathrm{kg} / \mathrm{ha} \\
\end{array}$} \\
\hline & & & & & $\%$ & $\%$ & \\
\hline $\mathrm{P}_{1}$ & & & & & $\mathbf{a}$ & $a b$ & $\mathbf{a}$ \\
\hline 1 - Vernolate & 3,60 & 567 & 0,813 & $1,43 \mathrm{~b}$ & 4,54 & 8,19 & $1.149 \mathrm{~b}$ \\
\hline 2 - Triflurahin & 0,96 & 764 & 1,202 & $1,57 \mathrm{ab}$ & 4,56 & 8,38 & $1.371 \mathrm{~b}$ \\
\hline 3 - Pendimethalin & 1,50 & 542 & 1,009 & $1,86 \mathrm{a}$ & 4,59 & 8,44 & $1.361 \mathrm{~b}$ \\
\hline 4 - Alachlor & 2,40 & 632 & 1,081 & $1,71 \mathrm{ab}$ & 4,91 & 8,24 & $1.246 \mathrm{~b}$ \\
\hline 5-Metribuzin & 0,63 & 802 & 1,145 & $1,43 \mathrm{ab}$ & 4,04 & 8,38 & $1.274 \mathrm{~b}$ \\
\hline 6 - Sem herbicida & -- & 481 & 0,775 & $1,61 \mathrm{a}$ & 4,56 & 7,74 & $1.132 \mathrm{a}$ \\
\hline $\mathbf{P}_{2}$ & & & & & $\mathbf{a}$ & b & b \\
\hline 7 - Vernolate & 3,60 & 572 & 0,822 & $1,44 \mathrm{~b}$ & 4,64 & 8,26 & $1.351 \mathrm{~b}$ \\
\hline 8 - Trifluralin & 0,96 & 700 & 1,114 & $1,59 \mathrm{ab}$ & 4,56 & 8,15 & $1.364 \mathrm{~b}$ \\
\hline 9 - Pendimethalin & 1,50 & 377 & 0,686 & $1,82 \mathrm{a}$ & 4,43 & 8,30 & $1.271 \mathrm{~b}$ \\
\hline 10 - Alachlor & 2,40 & 658 & 0,977 & $1,48 \mathrm{ab}$ & 4,80 & 8,03 & $1.319 \mathrm{~b}$ \\
\hline 11 - Metribuzin & 0,63 & 481 & 0,822 & $1,71 \mathrm{ab}$ & 4,57 & 7,98 & $1.382 \mathrm{~b}$ \\
\hline 12 - Sem herbicida & -- & 692 & 1,078 & $1,56 \mathrm{a}$ & 4,29 & 8,20 & $1.243 \mathrm{a}$ \\
\hline $\mathbf{P}_{3}$ & & & & & b & $\mathbf{a}$ & c \\
\hline 13 - Vernolate & 3,60 & 410 & 0,527 & $1,296 \mathrm{~b}$ & 4,12 & 8,42 & $1.510 \mathrm{~b}$ \\
\hline 14 - Trifluralin & 0,96 & 613 & 0,925 & $1,51 \mathrm{ab}$ & 4,08 & 8,64 & $1.358 \mathrm{~b}$ \\
\hline 15 - Pendimethalin & 1,50 & 484 & 0,781 & 1,61 a & 4,24 & 8,49 & $1.462 \mathrm{~b}$ \\
\hline 16 - Alachlor & 2,40 & 704 & 0,975 & $1,38 \mathrm{ab}$ & 4,32 & 8,57 & $1.476 \mathrm{~b}$ \\
\hline 17 - Metribuzin & 0,63 & 710 & 1,102 & $1,55 \mathrm{ab}$ & 4,30 & 8,50 & $1.424 \mathrm{~b}$ \\
\hline 18 - Sem herbicida & -- & 400 & 0,902 & 2,25 a & 4,18 & 8,33 & $1.114 \mathrm{a}$ \\
\hline F (herbicidas) & & 2,30 n.s. & 1,64 n.s. & $3,20^{*}$ & 1,64 ns. & 0,69 n.s. & $3,38^{*}$ \\
\hline F (populaçōes) & & 1,04 n.s. & 0,95 n.s. & 0,08n.s. & $7,20 * *$ & $3,40 *$ & $4,93^{*}$ \\
\hline C.V $\%$ & & 19,20 & 20,22 & 20,73 & 8,04 & 5,71 & 11,24 \\
\hline
\end{tabular}

(1) = amostragem feita aos 94 dias. Valores relativos a dez plantas.

(2) = amostragem em folhas feita aos 78 dias e, em gräos, na colheita.

MS = matéria seca

n.s. $=$ não significativo; * significativo a $5 \% ; *$ significativo a $1 \%$

$P_{1}=200.000$ plantas/ha; $P_{2}=300.000$ plantas/ha; $P_{3} 400.000$ plantas/ha.

Letras diferentes sobre as colunas e após os valores das colunas inđicam diferenças significattivas a nível de S\% (Teste de Tukey). 
Quadro 4. Resultados de nodulaçáo, teor de N e produção, no Experimento III, de 1978/79, de herbicidas e populaçóes de plantas em soja 'Santa Rosa', em solo argiloso. Médias de quatro repetiçóes.

\begin{tabular}{|c|c|c|c|c|c|c|c|}
\hline \multirow{3}{*}{ TRATAMENTO } & \multirow{3}{*}{$\begin{array}{l}\text { i. a. } / \mathrm{ha} \\
\mathrm{kg}\end{array}$} & \multicolumn{3}{|c|}{ Nódulos ${ }^{(1)}$} & \multicolumn{2}{|c|}{$N^{(2)}$} & \multirow{3}{*}{$\begin{array}{c}\text { PRODUÇÃO DE } \\
\text { GRÁOS } \\
\text { kg/ha } \\
\end{array}$} \\
\hline & & NÜMERO & PESO MS & UNITÁRIO & FOLHAS & GRÃos & \\
\hline & & & $\mathrm{g}$ & mg & $\%$ & $\%$ & \\
\hline \multicolumn{8}{|l|}{$P_{1}$} \\
\hline 1 - Vernolate & 3,60 & $517 a$ & $1,570 \mathrm{a}$ & 3,04 & 3,99 & 6,82 & $2.880 \mathrm{a}$ \\
\hline 2 - Trifluralin & 0,96 & $219 \mathrm{~b}$ & $0,611 b$ & 2,79 & 4,07 & 6,44 & $2.705 \mathrm{a}$ \\
\hline 3 - Pendimethalin & 1,25 & $385 a$ & $1,165 \mathrm{a}$ & 3,03 & 4,08 & 6,71 & $2.823 \mathrm{a}$ \\
\hline 4 - Alachlor & 2,40 & $418 a$ & $1,236 \mathrm{a}$ & 2,96 & 3,77 & 6,37 & $2.746 \mathrm{a}$ \\
\hline 5 - Metribuzin & 0,53 & $513 \mathrm{ab}$ & $1,504 a$ & 2,93 & 3,92 & 6,68 & $1,939 \mathrm{~b}$ \\
\hline 6 - Sem herbicida & -- & $608 a$ & $1,693 \mathrm{a}$ & 2,78 & 4,15 & 6,78 & $2.799 \mathrm{a}$ \\
\hline \multicolumn{8}{|l|}{$P_{2}$} \\
\hline 7 - Vernolate & 3,60 & $418 a$ & $1,139 \mathrm{a}$ & 2,72 & 4,22 & 6,87 & $3.125 \mathrm{a}$ \\
\hline 8 - Trifluralin & 0,96 & $335 b$ & $0,878 \mathrm{~b}$ & 2,62 & 4,03 & 7,18 & $2.844 a$ \\
\hline 9 - Pendimethalin & 1,25 & $460 \mathrm{a}$ & $1,229 \mathrm{a}$ & 2,67 & 4,05 & 6,62 & $3.243 \mathrm{a}$ \\
\hline 10 - Alachlor & 2,40 & $366 \mathrm{a}$ & $1,221 \mathrm{a}$ & 3,33 & 4,10 & 6,92 & $2.663 \mathrm{a}$ \\
\hline 11 - Metribuzin & 0,53 & $414 a b$ & $1.115 \mathrm{a}$ & 2,69 & 3,95 & 6,45 & $2.132 \mathrm{~b}$ \\
\hline 12 - Sem herbicida & - & $421 \mathrm{a}$ & $2,319 \mathrm{a}$ & 5,51 & 4,11 & 6,33 & $2.792 \mathrm{a}$ \\
\hline F (herbicidas) & & $5,75^{* *}$ & $5,99 * *$ & 0,92 n.s. & $1,06 \mathrm{n} . \mathrm{s}$. & 0,96 n.s. & $6,90 * *$ \\
\hline F (populaçōes) & & 1,40 n.s. & $3,62 \mathrm{n} . \mathrm{s}$ & $0,13 \mathrm{n} \cdot \mathrm{s}$ & 1,45 n.s. & $0,82 \mathrm{n}$.s. & $1,80 \mathrm{n} \cdot \mathrm{s}$ \\
\hline C.V. $\%$ & & 12,19 & 12,47 & 18,10 & 5,63 & 5,27 & 14,30 \\
\hline
\end{tabular}

(1) = amostragem realizada aos 71 dias da emergência. Valores por dez plantas. MS = matéria seca

(2) = amostragem realizada aos 71 dias da emergência

$P_{1}=150.000$ plantas por hectare, $P_{2}=250.000$ plantas por hectare

${ }^{* *}=$ significativo ao nível de $1 \%$, teste de Tukey, n.s. = não significativo

Letras diferentes após os valores, nas colunas de cada populaçāo, indicam diferenças significativas ao nível de $5 \%$ pelo teste de Tukey. 
los, diferindo significativamente da testemunha.

Para o peso total de matéria seca de nódulos, foram verificadas diferenças significativas entre herbicidas, com interação entre solos e herbicidas. No solo argiloso, os tratamentos com trifluralin, vernolate e metribuzin, com valo res mais baixos, foram diferentes daqueles com pendimethalin e da testemunha. No solo barrento, os tratamentos com vernolate e pendimethalin apresentaram os valores mais baixos e foram diferentes, a nivel de $1 \%$, daquele com alachlor e da testemunha.

A diferença ocorrida no Experimento I parece ser devido ao grande número de nódulos presentes, muito mais elevado do que nos outros dois. Considerando que a inoculação, nos três experimentos, foi realizada da mesma forma e com o mesmo inoculante, o desenvolvimento e ação das bactérias, nesse caso, parecem ter sido favorecidos pelas condições do solo. O $\mathrm{pH}$ mais elevado nesse experimento poderia ser um dos fatores. No solo do Experimento II, o $\mathrm{pH}$ era apenas 4,8, o que seguramente contribuiu para a redução do número de nódulos, uma vez que, segundo Gibson (14), a multiplicação das bactérias Rhizobium é afetada em $\mathrm{pH}$ abaixo de 5,3 . Os valores baixos de número de nódulos encontrados no
Experimento III são ma is difíceis de explicar já que o $\mathrm{pH}$ naquele solo era de 6,6.

Não foi encontrado na literatura nenhum trabalho relacionando diferentes populações de plantas de soja com a nodulação, o que deve ser considerado importante tendo em vista a nutrição nitrogenada desta cultura.

$\mathrm{O}$ vernolate parece ter tido alguma influência sobre o desenvolvimento dos nódulos no Experimento II, mas não reduziu o seu número significativamente.

A reducão do número e peso de matéria seca de nódulos no Experimento III pelo trifluralin parece estar relacionada com a textura do solo e melhores condições de umidade, favorecendo, de alguma forma, o con tato do herbicida com as bactérias.

Nos vasos, a nodulação foi avaliada pelo número e peso de matéria seca de nódulos aos 30 dias, portanto, ainda, em processo inicial de formação. Isso possibilitou verificar, em comparação com as condições de campo, se algum dos herbicidas estudados teria apenas ação inicial sobre a nodulação ou efeito mais longo.

Os números de nódulos obtidos, por planta, mostram que a nodulação estava realmente em seu início, quando comparado aos valores obtidos no campo, entre 71 e 84 dias.

Quadro 5. Número e peso de matéria seca de nódulos, por planta, aos 30 dias após a emergência, em experimento de herbicidas em vasos, em casa-de-vegetação. Médias de três repetições.

\begin{tabular}{|c|c|c|c|c|c|c|c|}
\hline \multirow{2}{*}{ TRATAMENTO } & \multirow{2}{*}{ i.a. $/$ ha } & \multicolumn{2}{|c|}{ NÚMERO } & \multicolumn{2}{|c|}{ PESO M.S. } & \multicolumn{2}{|c|}{ PESO UNITÁRIÓ } \\
\hline & & $\mathbf{A}$ & B & A & B & A & B \\
\hline & kg & & & $\mathrm{mg}$ & $\mathrm{mg}$ & mg & mg \\
\hline 1. Trifluralin & 0,86 & $3,07 \mathrm{~b}$ & $1,55 \mathrm{~b}$ & $1,27 \mathrm{~b}$ & $2,71 \mathrm{ab}$ & 0,413 & 1,748 \\
\hline 2. Vernolate & 3,60 & $3,63 b$ & $1,00 \mathrm{~b}$ & $1,45 b$ & $0,55 \mathrm{~b}$ & 0,399 & 0,550 \\
\hline 3. Metribuzin & 0,63 & $3,89 \mathrm{ab}$ & $2,19 \mathrm{ab}$ & $1,79 \mathrm{~b}$ & $2,82 \mathrm{ab}$ & 0,460 & 1,288 \\
\hline 4. Alachlor & 2,40 & $5,59 \mathrm{ab}$ & $3,41 \mathrm{ab}$ & $5,00 \mathrm{ab}$ & $6.67 \mathrm{a}$ & 0,894 & 1,956 \\
\hline 5. Pendimet halin & 1,50 & $4,26 \mathrm{~b}$ & $0,85 b$ & $9,28 a$ & $1,32 \mathrm{~b}$ & 2,178 & 1,553 \\
\hline 6. Sem herbicida & - & $8,11 \mathrm{a}$ & $2,19 \mathrm{a}$ & $7,66 \mathrm{a}$ & $5,39 \mathrm{a}$ & 0,944 & 2,461 \\
\hline $\mathbf{F}$ & & $* *$ & $* *$ & $* \bullet$ & $\bullet$ & - & - \\
\hline
\end{tabular}

M.S. = peso de matéria seca

$\mathrm{A}=$ solo argiloso

$\mathrm{B}=$ solo barrento

Valores, nas colunas, seguidas de letras iguais, não diferem entre si, ao nível de $5 \%$ (teste de Tukey). Ocorreu interação entre solos e herbicidas para o peso de nódulos. Para o número de nódulos houve diferença significativa entre solos ao nivel de $1 \%$. 
O que chama a atenção é o fato de que no solo muito argiloso, o mesmo do Experimento II, o número e o peso de nódulos foram bem maiores, em média, mas não o peso unitário, do que no solo barrento. Is so contraria o que ocorreu no campo, considerando-se que o solo barrento, dos vasos, é semelhante ao argiloso dos Experimentos I e III. Parece ter havido uma compensação para crescimento dos nódulos, pois onde estes ocorriam em maior número, houve menor crescimento e vice-versa.

Não houve interação entre solos e herbicidas, em vasos, mostrando, este fato, que a ação destes foi semelhante nos dois solos quanto ao número de nódulos. A redução do número de nódulos pelos herbicidas trifluralin, pendimethalin e vernolate é facilmente compreensivel, pois são inibidores de mitose e podem bem inibir a multiplicação das bactérias. A ação do metribuzin, que é um potente inibidor da fotossintese sobre as bactérias, não deve ter sido igual à dos herbicidas citados, mas, seguramente, sobre qualquer outro processo metabólico.

Os pesos unitários dos nódulos, em vasos, indicam um efeito inibitório por parte do vernolate, reduzindo o seu tamanho. Outros autores não observaram qualquer efeito inibitório pelo vernolate sobre a nodulação (Parker e Dowler, 31; Giardini et al., 13).

Efeitos depressivos causados pelo trifluralin já foram verificados anteriormente por Hamdi e Tewfik (16), que, aplicando o herbicida no dia da semeadura de Vigna sinensis, verificaram redução do número de nódulos, mas quando aplicaram 27 dias antes da semeadura, chegaram a observar efeito es timulante. Também Kust e Struckmeyer (22) verificaram redução do número de nódulos pelo trifluralin em soja e Parker e Dowler (31), com aplicação deste herbicida, constataram redução sign ificativa do peso de matéria seca de nódulos.

Por outro lado, Lorenzi e Araujo (23) só observaram efeito depressivo do trifluralin em Rhizobium autóctone e não em soja inoculada e Giardini et al. (13) não verificaram qualquer efeito inibitório por parte do trifluralin em nodu- lação de soja inoculada, em dois anos consecutivos, em solo barrento. $\mathrm{Da}$ mesma forma, não foi encontrado qualquer efeito depressivo por parte do alachlor pelos mesmos autores $(13,23)$. Não foi encontrada na literatura qual quer referência à ação de metribuzin sobre bactérias Rhizobium ou nodulação, talvez por ser composto de uso mais recente.

Os resultados, às vezes discordantes, levam a concluir que, além das condições peculiares dos solos, a estirpe das bactérias poderia também reagir diferentemente à ação dos herbicidas.

Crescimento inicial da soja

Os valores de pesos de matéria seca de raízes e de parte aérea, nas três épocas de amostragem, estão representados na Figura 1.
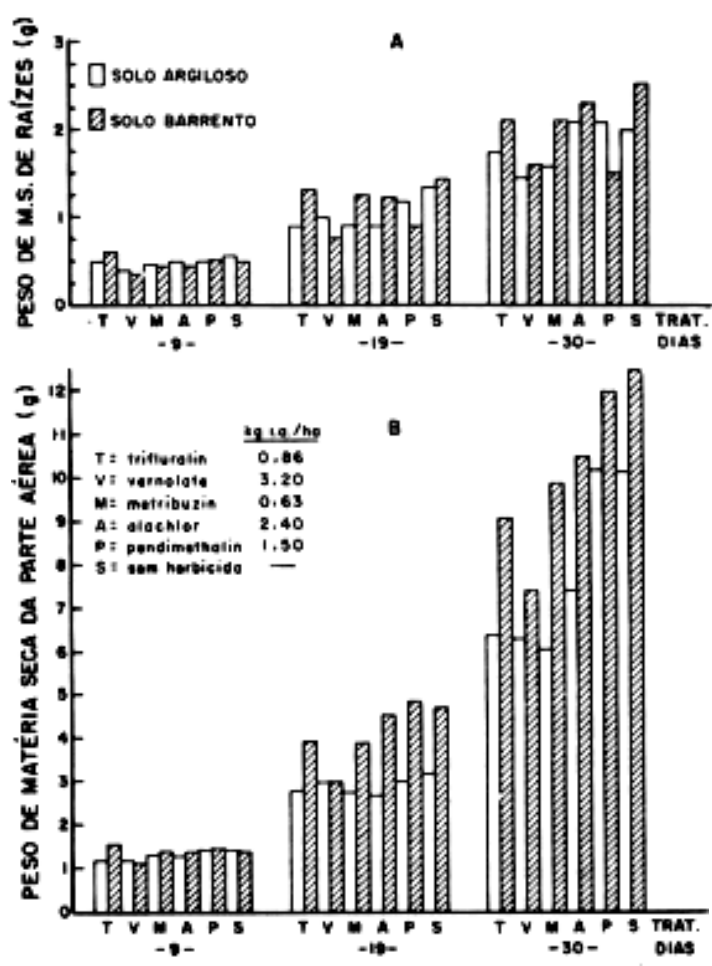

Figura 1. Pesos de matéria seca de raizes $(A)$ e de parte aérea (B) no experimento de herbicidas em soja cultivar Santa Rosa, em casa-de-vegetação.

Ocorreram diferenças entre solos e herbicidas, com interação entre ambos, para raizes, aos 19 dias. O tratamento com vernolate, com menor peso, diferiu da testemunha no solo barrento. No ar- 
giloso, não ocorreu diferença significativa, mas, em ambos os solos, os valores nas testemunhas foram mais elevados para esse parâmetro. Na primeira e terceira amostragens, não foram encontradas quais quer diferenças.

Para o peso da parte aérea nao foi verificada qualquer diferença entre tratamentos na primeira amostragem. Nas duas seguintes, houve diferença entre solos e herbicidas, com interação entre ambos, na segunda. Nesta, à semelhança do peso de raízes, só ocorreram diferenças entre tratamentos no solo barrento. $O$ tratamento com vernolate apresentou o valor mais baixo, diferindo daqueles com alachlor, pendimethalin e da testemunha. $\mathrm{Na}$ terceira amostragem, verificou-se que os tratamentos com trifluralin, vernolate e metribuzin foram significativamente menores que aqueles com pendimethalin e da testemunha.

Comparando-se os dois solos, observou-se que o crescimento das plantas de soja foi mais vigoroso no solo barrento, que apresentava condições físicas e químicas mais favoráveis ao crescimento inicial (Quadro 1).

Os sintomas dos herbicidas verificados nos vasos eram semelhantes aos que ocorreram nos experimentos de campo, mas em grau bem menor. O trifluralin e o pendimethalin inibiram a formação de raízes laterais na camada superficial. Essa inibição era bem evidente no solo muito argiloso e, menos pronunciada, por parte do trifluralin, no solo barrento. O vernolate causou redução de comprimento também das raízes secundárias. A inibição de crescimento de raízes laterais em soja já é conhecida para o trifluralin (28), mas, para o vernolate, não foi encontrado registro desse efeito em soja; nem para o pendimethalin, talvez, por ser de uso mais recente. A ação deste era esperada, por pertencer ao mesmo grupo químico do trifluralin.

Quanto à parte aérea, a redução de peso pelos herbicidas trifluralin, vernolate e metribuzin no solo muito argiloso foi bem pronunciada e um pouco menos inten sa pelo alachlor. A diferença de pesos, considerando os dois solos, contraria a expectativa inicial de que no solo argiloso haveria menor injúria às plantas. O maior"vigor delas no solo barrento, parece ter conferido também mais resistência à ação dos herbicidas.

Pelo experimento em vasos, verificouse que o sistema radicular da soja é bastante tolerante à ação de herbicidas, visto que foi pouco afetado por trifluralin, pendimethalin e vernolate e, praticamente, nada por alachlor ou metribuzin.

A ocorrência de efeitos fitotóxicos, por parte desses herbicidas, já é conhecida e registrada na literatura $(5,8,10,20,22$, $30,34,35)$ e concordam com os resultados observados em vasos e nos experimentos de campo.

\section{Teor de nitrogênio em folhas e grãos}

A análise do teor de $\mathrm{N}$ foi realizada entre 71 e 84 dias, quando a maior parte desse nutriente já fora absorvida pela soja $(2,24)$.

Os teores encontrados nos três experimentos podem ser considerados elevados, quando comparados aos obtidos por Bataglia et al. (2) com o mesmo cultivar e em solo semelhante aos aqui relatados.

Em função da população de plantas, a única diferença ocorrida para o teor de $\mathrm{N}$ foi verificada no Experimento II, em que a maior população resultou em menores teores do nutriente por planta. Partindo do fato de que todo o $\mathrm{N}$ fornecido às plantas provinha das bactérias que nodulavam as raízes, uma vez que não houve qualquer outro fornecimento desse nutriente, parece ter havido uma redução de eficiência das bactérias com maior número de plantas, já que não ocorreu qualquer diferença, no número ou no peso dos nódulos, entre populações neste experimento. Outra hipótese seria a existência de $\mathrm{N}$ no solo, tendo em vista o elevado teor de matéria orgânica que suplementaria o $\mathrm{N}$ fornecido pelas bactérias. Neste caso, o maior número de plantas da densidade maior determinaria menor quantidade de $\mathrm{N}$ disponivel por planta.

Os resultados de decréscimo do teor de $\mathrm{N}$, com o aumento da população de plantas, no Experimento II, concorda com o verificado por Buttery (6) que, no entanto, trabalhou com variação 
bem grande de populações e analisou a planta toda. Quanto aos outros experimentos, a variação de população não parece ter sido suficiente para causar qualquer alteração no teor de $\mathrm{N}$.

Os teores de N, encontrados nos grãos, nos experimentos I e II, são bastante elevados, quando comparados aos determinados por Bataglia et al. $(2,3)$, concordando aqueles do Experimento III, com estes autores.

Não houve qualquer efeito de herbicidas sobre o teor desse nutriente nos três experimentos.

Quanto aos efeitos de população de plantas, o $\mathrm{N}$ ocorreu em teores mais elevados com populações maiores nos experimentos I e II e tendência igual no III, ocorrendo o inverso em relação ao encontrado em folhas, no flore scimento. A explicação desse fato parece ser que as diferenças de produção, por planta foram maiores do que a diferença do teor de $\mathrm{N}$ encontrado nas folhas, determinando, com a translocação do nutriente para os grãos, uma concentração maior nestes, por planta.

A não interferência de herbicidas no teor de $\mathrm{N}$ em grãos, concorda com os resultados de trabalhos existentes sobre o assunto. Não foi encontrado efeito de trifluralin sobre o teor de $\mathrm{N}$ e de proteína $(7,21)$, de trifluralin ou de vernolate (21) ou de vernolate (17).

De modo geral, pode-se dizer que as populações de plantas ou os herbicidas utilizados na soja, muito pouco influíram no teor de $\mathrm{N}$ em grãos, estando este muito mais dependente das condições de solo e de clima.

Produção de grãos

As produções médias das populações de plantas foram iguais no Experimento I, ao passo que no Experimento II, elas se elevaram com o aumento do número de plantas. Levando em consideração que as densidades 1 e 2 de ambos os experimentos eram praticamente iguais e as culturas se desenvol veram exatamente na mesma época, as diferenças de produção foram determinadas pelas diferentes características dos solos. Deve ser lembrado que, no Experimento I, em solo argiloso, as plantas apresentaram crescimento maior em termos de altura e peso.
Quanto à fertilidade, o solo do Experi mento II apresentava ligeira superioridade no teor de $\mathrm{Ca}$ e de $\mathrm{K}$ e teor bem mais elevado de matéria or gânica. A razão mais plausivel para as diferenças de produção de grãos é a melhor retenção de água no solo muito argiloso e com mais matéria orgânica, em ano de distribuição irregular de chuvas.

A maior produtividade alcançada no Experimento III foi causada pela maior e mais bem distribuída precipitação pluviométrica ocorrida nesse ano, quando se registraram também, temperaturas médias mais baixas durante todo o ciclo da cultura.

Os resultados de produção encontrados em função das diferentes populações de plantas, são normais, quando comparados à literatura universal. Ora há respostas positivas de incremento de produção com o aumento da população nas linhas $(6,15,26)$, ora não há resposta $(1,4,9,18,27,30,33)$. Além de certos limites de população, a produção pode mesmo decrescer $(12,26,29)$. As diferentes características dos cultivares e dos solos e as diferentes condições climáticas são as responsáveis pelas respostas diferenciais que ocorrem em cada caso.

Nos dois primeiros experimentos, não se verificou nenhuma redução de produção total causada por qualquer dos herbicidas aplicados, mesmo tendo sido constatados alguns efeitos fitotóxicos causados pelos herbicidas tr iflu ralin, pendimethalin ou vernolate.

Chama a atenção a menor produção nos tratamentos testemunhas com as três densidades de plantas no Experimento II. Essa redução foi mais acentuada com a po pulação maior e reforça a hipótese da competição com as plantas daninhas, presentes até os 43 dias e, controladas pelos herbicidas nas outras parcelas. Mesmo em número não elevado, as plantas daninhas devem ter afe tado o des envolvimento da soja com a população mais alta.

No Experimento III, o único herbicida que afetou a produção foi o metribuzin, o que se deve à redução do número de plantas no início do ciclo. As plantas que não morreram apresentaram plena recuperação e carga normal de vagens. 
Outros autores têm constatado sintomas de fitoxicidade, até em grau se vero, pelo herbicida trifluralin, sem que houvesse redução de produção $(10,20$, 22, 34). O mesmo já foi verificado com pendimethalin (35), com vernolate (10) e com metribuzin (8). Em alguns casos, foram verificadas reduções de produção com trifluralin $(5,11)$, com vernolate $(11$, 33), com pendimethalin (35) ou com metribuzin $(11,19)$.

As diferentes respo stas da cultura da soja aos herbicidas sobre a produção decorrem de vários fatores: a intensidade dos danos iniciais, a capacidade de recuperação das plantas, o que está ligado às características genéticas do cultivar, e, tempo de dissipação do herbicida no solo.

\section{LITERATURA CITADA}

1. Bastidas, R.G.; Camacho, M.L.H.; Londono, J.F.; Buitrago, G.L.A. \& Davis, F.. Efecto de la densidad de población sobre algunas características agronómicas y fisiológicas de tres genotipos de soya, Glycine max (L.) Merr., bajo condiciones tropicales. Acta Agronomica, Palmira, XXI:37-50, 1971.

2. Bataglia, O.C.; Mascarenhas, H.A.A.; Teixeira, J.P.F. \& Tisseli F o O.. Acumulo de matéría seca e nutrientes em soja cultivar Santa Rosa. Bragantia 35:237-247, 1976.

3. Bataglia, O.C.; Mascarenhas, H.A.A. \& Tissel F ${ }^{\circ} \mathrm{O}$.. Composição mineral das sementes de nove cultivares de soja. Bragantia 36: XLVII-L, 1977. (Nota 12).

4. Bueno, L.C.S.; Sediyama, C.S. \& Vieira, C. Efeitos de espaçamentos, densidades e época de plantio sobre duas variedades de soja. Experimentiae, Viçosa, 20:263-287, 1975.

5. Burnside, O.C. Tolerance of soybean cultivars to weed competition and herbicides. Weed Science 20:294-297, 1972.

6. Buttery, B.R.. Effects of plant population and fertilizer on growth and yield of soybeans. Canadian J. Plant Science 49:659-673, 1969.

7. Bzikow, M.A.; Byasov, K.Kh. \& Misik, N.A (The effects of herbicides on the dynamics of soil nutrients and soybean yield and quality). Khimiya $\mathrm{v}$ sel'skom Khozyaistve 9: 45-50, 1971. URSS. In: Weed Abstracts 21: $2.800,1972$

8. Coble, H.D. \& Schrader, J.W.. Soybean tolerance to metribuzin. Weed Science 21:308309, 1973.

9. Doss, B.D. \& Thurlow, D.L.. Irrigation, row width and plant population in relation to growth characteristics of two soybean varieties. Agron. Journal 66:620-623, 1974.

10. Dowler, C.C. \& Hauser, E.W.. Factors affecting the response of soybeans to trifluralin, vernolate and benefin. Southern Weed Sci. Soc. 22. 1969. Proc. (Abstract), 360.
11. EMBRAPA - Ponta Grossa. Controle químico de invasoras na cultura da soja, 75-76, 1976. (Comunicado Técnico 04), 25p.

12. Felton, W.L.. The influence of row spacing and plant population on the effect of weed competition in soybeans (Glycine max), Australian J. Exp. Agri. An. Husb. 16:926-931, 1976.

13. Giardini, A.R.; Lopes, E.S. \& Deuber, R.. Influência de herbicidas na nodulaçấo da soja (Glycine max L. Merr.). Planta Daninha 2: 21-32, 1979 .

14. Gibson, A.H. Limitations of dinitrogen fixation by legumes. In: Internat. Symposium on Nitrogen Fixation 1. Ed. Newton, W.E. e Nyman, C.J., 1976. Proc. p. 415.

15. Gray, R.W... Soybean spacing in a high rainfall environment. East Afric. Agric. For. J. 32: 265-268, 1967

16. Hamdi, Y.A. \& Tewfik, M.S.. Effect of the herbicide trifluralin on nitrogen fixation in $R \mathrm{hi}$ zobium japonicum and Azotobacter and on nitrification. Aeta Microbiologica, Cairo, 18:53-57, 1969.

17. Hardcastle, W.S.; Wilkinson, R.E. \& Young, C. T. Metribuzin effects on seed constituents of soybean varieties. Weed Science 22:575. 577. 1974.

18. Hicks, D.R.; Pendleton, J.W.; Bernard, R.L. \&

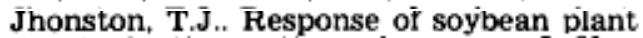
types toplanting pattern. Agronomy J. 61: 290-293, 1969 .

19. Holowid, J.R.; Jeffery, L.S. \& McCutchen, T.C.. Influence of soll types on soybean response to chlorbromuron, linuron and metribuzin. Am. Meeting Southern Weed Science Soc. 30, 1977. Proc. p. 51.

20. Johnson, B.J.. Effects of sequential herbicide treatments on weeds and soybeans. Weed Science 19:695-700, 1969.

21. Johnson, B.J. \& Jellum, M.D.. Effect of pesticides on chemical composition of soybean seed (Glycine max). Agronomy J. 61:379-380, 1969.

22. Kust, C.A. \& Struckmeyer, R.E.. Effects of trifluralin on growth, nodulation and anatomy of soybeans. Weed Science 19:147-152, 1971.

23. Lorenzi, H.J. \& Araujo, J.W.. Estudo da açáo de alguns herbicidas na fixação simbiótica do $\mathrm{N}$ em plantas de soja (Glycine max L. Merr.). Reunion Latinoamericana sobre Rhizobium. 7. Resistência, Rep. Argentina, 1974. Anales p.222-231.

24. Mascarenhas, H.A.A. Acúmulo de matéria seca, absorção e distribuiçáo de elementos durante o ciclo vegetativo da soja. Campinas, Instítuto Agronómico, 1973. 43p. (Boletim Técnico 6).

25. Melfi. A.J.; Girardi, A.V. \& Moniz, A.C.. Mineralogia dos solos da Estaçáo Experimental "Theodureto de Camargo" em Campinas. Bragantia 25:9-30, 1966.

26. Minor, H.C. \& Jackobs, J.A. Influence of planting date, row width and population on yied components of two varieties of soybean in Central India. Univers. Illinois. Agron. Abstracts 9-12:44, 1969.

27. Neumaier, N.. Efelto da fertilidade do solo, época de plantio e população sobre o comportamento de duas cultivares de soja (Gly- 
cine $\max$ L. Merr.). Univers. Federal. RGS, Porto Alegre, 1975.127 p. (Dissertaçâo).

28. Oliver, L.R. \& Frans, R.E.. Inhibition of cotton and soybean roots from incorporated trifluralin and persistence in solls. Weed Science 16:199-203, 1968.

29. Osafo, D.M. Effects of population density on yields of two soybean (Glycine max) varieties in Ghana forest zone. Exptl. Agricult 13:235-240, 1977.

30. Pant, T. \& Joshi, M.C.. Note on response of soybean variety 'Bragg' to plant population and planting geometry in Kuma on Hills. Patnugar J. Research 2:225-226, 1977.

31. Parker, M.B. \& Dowler, C.C. Effects of nitrogen with trifluralin and vernolate on soybeans. Weed Science 24:131-133, 1976.
32. Reis, M.S., et al. Comportamento de duas variedades de soja em diferentes espaçamentos de plantio e niveis de adubaçáo, Triângulo Mineiro. Rev. Ceres, Viçosa, 24:306-337, 1977.

33. Reis, W.D. \& Sherwood, L.V.. Effect of row spacing seedling rate, and potassium and calcium hydroxide additions on soybean yields on soils in southern Illinois. Agronomy J. 57:431-433, 1965.

34. Voll, E.. Avaliaçáo preliminar de herbicidas em PPI e PE na cultura da soja. Reuniáo Conjunta de Pesquisa de Soja da Região Sul, 5, 1977. 2p. (Mimeo.).

35. Wilson, H.P.; Hines, T.E. \& Dunton, J.E. Jr.. Activity of penoxalin in soybeans. Northeast Weed Scl. Soc. 31. 1977, Proc. p. 70-77. 